Research Article

\title{
Investigation of Sandstone Mesostructure Damage Caused by Freeze-Thaw Cycles via CT Image Enhancement Technology
}

\author{
Hui Liu $\mathbb{D}^{1},{ }^{1}$ Gengshe Yang, ${ }^{1}$ Yehui Yun, ${ }^{1}$ Jianghao Lin, ${ }^{1}$ Wanjun Ye, ${ }^{1}$ Huimei Zhang, \\ and Yao Zhang ${ }^{1}$ \\ ${ }^{1}$ College of Architecture and Civil Engineering, Xi'an University of Science and Technology, Xi'an, China \\ ${ }^{2}$ Department of Mechanics, Xi'an University of Science and Technology, Xi'an, China \\ Correspondence should be addressed to Hui Liu; liuhui2006@xust.edu.cn
}

Received 21 July 2020; Revised 13 September 2020; Accepted 25 September 2020; Published 15 October 2020

Academic Editor: Hang Lin

Copyright ( 92020 Hui Liu et al. This is an open access article distributed under the Creative Commons Attribution License, which permits unrestricted use, distribution, and reproduction in any medium, provided the original work is properly cited.

\begin{abstract}
The mesostructures of rocks determine their macromechanical properties. These rock mesostructures may be altered by the freezethaw cycles in cold regions. In this regard, this paper proposes a quantitative evaluation method based on computed tomography (CT) scanning technology for investigating the mesostructure and damage characteristics of sandstone subjected to freeze-thaw conditions. CT scan images of two sandstones with different grain sizes were obtained after 0, 20, 40, 60, 80, and 100 freeze-thaw cycles, using a high-precision CT scanner. Based on the microphysical information contained in these CT images, pseudo-colorenhancement of the CT images of rocks subjected to freeze-thaw cycles was realized. The use of such a pseudo-color-enhancement technique can improve the resolution of CT images. Thus, particle detachment, crack initiation, crack propagation, and increased porosity due to the volumetric expansion of water inside the rock could be detected and clearly observed. Furthermore, a numerical expression for the mesostructure and damage information contained in the pseudo-color-enhanced images is presented herein; this serves as a convenient method for quantitative analyses of sandstone damage under freeze-thaw cycles. An analysis of the pseudo-color-enhanced images shows that, under freeze-thaw cycles, damage propagation in sandstone originates from existing damage or defect sites. After the stages of crack (pore) formation, penetration, and propagation, the freeze-thaw cycle-induced damage increases gradually, while the effective bearing area of the rock decreases continuously. Herein, a schematic of a conceptual model for the freeze-thaw cycle-induced deterioration in sandstone mesostructures is presented. Damage propagation models for sandstones with two different grain sizes subjected to freeze-thaw cycles were also developed. Based on the damage mechanics theory, a damage variable expressed in terms of the pore area was defined. Moreover, the relationship between this damage variable and the freeze-thaw cycles was established.
\end{abstract}

\section{Introduction}

In the cold western regions of China, for the construction of infrastructure and the development of mineral resources, porous sandstone such as the Permian Shihezi Formation, quartz-cemented sandstone such as the Shanxi Formation, and argillaceous cemented sandstone such as the Jurassic Zhiluo Formation are widely employed. These form one of the principal aquifers in engineering geology. Sandstone is a complex engineering material featuring naturally occurring damage; it contains cracks and pores, which, in turn, may store gases or water. Sandstone is highly porous and capable of significant water absorption; however, it undergoes changes in its strength after encountering water. Thus, in cold regions where freeze-thaw cycles are common, it is necessary to assess the effects on the strength of sandstone to ensure appropriate integrity and maintenance of engineering projects in such regions [1-5].

In sandstone with initial damage, such as pores and microcracks, the primary effect of freeze-thaw cycles is the generation, propagation, and connection of these existing defects [6-8]. Although numerous researchers have studied the deterioration caused by freeze-thaw cycles, these previous studies have mainly focused on macroscopic physical 
and mechanical properties [9-12]. Very few studies have considered the changes in rock structures at the microscale [13-18]. According to the basic principle of geotechnical damage mechanics [19-21], the destruction of sandstone in cold regions is a process of cumulative damage. Although it is possible to evaluate these damage mechanisms through triaxial rock tests, mesodamage processes cannot be evaluated adequately. It is difficult to observe internal damage in rock materials through traditional means. Thus, it is necessary to combine macroscopic and mesoscopic methods in order to evaluate sandstone damage mechanics in cold regions.

The development of computed tomography (CT) technology has enabled the observation of internal damage in rock materials; using CT, the internal structure, composition, material, and defects of the target object can be clearly viewed in the form of two-dimensional cross-sectional images or three-dimensional images, without damaging the actual specimen. Raynaud developed a laboratory CT scanner for compressed rock samples and studied the development of internal cracks in compressed rock samples [22]. Yang et al. studied the initial damage properties of rocks using a medical CT scanner and derived a rock damage variable equation based on the CT results [23, 24]. Subsequently, Ge et al. applied CT to study the mesomechanical behavior of geotechnical materials under different loads $[25,26]$. Yang observed the microstructure of natural gas hydrates occurring in porous media using microfocus CT [27]. Watanabe developed a method for tracking soil particles using CT images and calculated their movement [28]. Zhang et al. performed triaxial tests using X-ray CT on three types of SRM samples with identical rock block contents but different grain size distributions [29]. Ma et al. evaluated the mesodamage characteristics of shale under hydration using CT [30]. Analyses of the cracking characteristics of rock and soil aggregates via CT testing have also been reported [31]. As discussed above, a majority of previous research has employed CT methods to determine the existence of cracks, pores, and other defects in engineering materials. A change in density is reflected by the mean variation in the regional CT number; alternatively, the overall mean CT number or variance of the scanned section can be used to analyze the microcrack evolution trend in the same section. It is not possible to quantitatively determine the size, shape, and spatial position of cracks using existing CT analysis methods. Conventional processing of damage information neglects the heterogeneity of rock microstructures and obscures the location and development of damage. Thus, existing CT analysis methods are unsuitable for quantitatively characterizing the damage mechanism in rocks subjected to freezethaw cycles.

For a quantitative investigation of the mesodamage characteristics of sandstones subjected to freeze-thaw cycles using CT techniques, this study proposes a CT image processing method based on CT scanning and an image enhancement technique (CT-IET). In addition, characteristics of mesodamage propagation are investigated for two sandstone samples. The influence of particle size and initial damage on the freeze-thaw cycle-induced damage in sandstone is analyzed using the proposed CT pseudo-color image enhancement method. This paper presents a novel method for quantitative analyses of rock damage in cold regions.

\section{Experiments}

\subsection{Apparatus}

2.1.1. Freeze-Thaw Cycle System. A dynamic constant temperature control system, that is, a constant high- or lowtemperature liquid bath circulation device (XT5701LT), was used to accurately control the temperature of the rocks, with constant fluctuations of $+0.1^{\circ} \mathrm{C}$ to $+0.5^{\circ} \mathrm{C}$ over the temperature range of $-50^{\circ} \mathrm{C}$ to $+90^{\circ} \mathrm{C}$ (Figure 1). Freezing is realized using a compressor and a condenser; a minimum temperature of $-50^{\circ} \mathrm{C}$ could be achieved (accuracy of $\pm 0.1^{\circ} \mathrm{C}$ ). A freezing temperature of $-20^{\circ} \mathrm{C}$ was used in these experiments; the thawing temperature was $20^{\circ} \mathrm{C}$. The operational parameters for the instrument, including the freezing time, freezing temperature, thawing time, and thawing temperature, could be adjusted via a central control panel.

2.1.2. Scanning System. The GE LightSpeed 64 VCT X-ray spiral CT machine is a high-speed, noninvasive image acquisition instrument. It uses a $64 \times 0.625 \mathrm{~mm}$ detector unit. It features a maximum coverage of $40 \mathrm{~mm} /$ circle and is capable of scanning submillimeter layer thicknesses in any mode; its isotropic resolution is as high as $0.30 \mathrm{~mm}$, and the image resolution is better than that of previous CT scanning equipment by a factor of approximately 40 (Figure 1).

2.1.3. Fixture for the Rock Samples. The fixture for the rock samples was fabricated using Plexiglas (Figure 1), which does not create additional artifacts on the rock samples. This fixture is used to stabilize the rock samples during scanning; it should be noted that the scans for different freeze-thaw cycles are conducted at the same layer depth.

2.2. Sample Preparation. The samples used in the experiments were obtained from Shaanxi Province; these sample had been subjected to seasonal freeze-thaw cycles. Two red sandstone samples from Shaanxi Province with different granularities were selected for the experiments:

(1) Coarse-grained sandstone from Xianyang, Shaanxi Province: this sandstone has a uniform brownish red color, uniform texture, large pores, poor compactness, and a particle size of $0.5-2 \mathrm{~mm}$. It is cemented with gravel and mud and primarily composed of feldspar, quartz, and muscovite.

(2) Fine-grained sandstone from Weinan, Shaanxi Province: this sandstone has a uniform light brownish red color, uniform texture, small internal pores, good compactness, and a particle size of $0.05-0.25 \mathrm{~mm}$. It is cemented with gravel and mud and primarily composed of feldspar, quartz, and muscovite. 


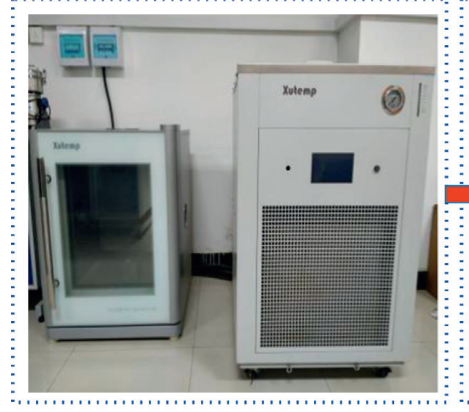

Freeze-thaw cycle system

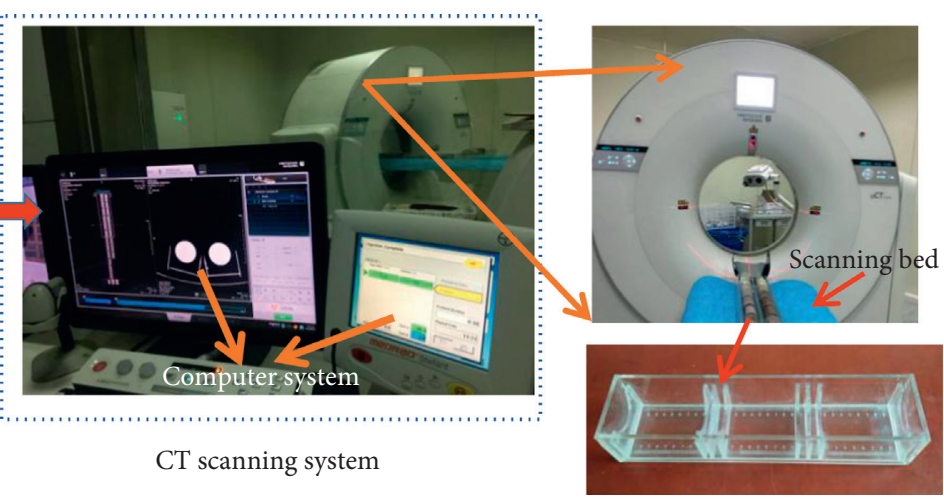

Rock sample fixture

Figure 1: Experimental apparatus.

All the rock samples were obtained from an intact, unweathered sandstone without any visible joints; the samples were obtained using water drilling. Thereafter, these samples were shaped into cylinders with a diameter of $50 \pm 1 \mathrm{~mm}$ and height of $100 \pm 1 \mathrm{~mm}$. Thus, six samples were obtained and categorized into two groups, each with three samples (Figure 2). Samples M1, M2, and M3 represent finegrained sandstone, whereas samples A1, A2, and A3 represent coarse-grained sandstone. The physical parameters of the rock samples are listed in Table 1.

\subsection{Experimental Conditions and Procedures}

2.3.1. Freeze-Thaw Cycle Conditions. The primary goal of the experiments in this study was to observe the changes and damage in the internal microstructures of the rock samples when subjected to different freeze-thaw cycles. The constant high- or low-temperature liquid bath circulation device (XT5701LT) at the School of Architecture and Civil Engineering at Xi'an University of Science and Technology was used to realize the different freeze-thaw cycles; each freezethaw cycle lasted for $16 \mathrm{~h}$. At the start of the cycle, the temperature is reduced from +20 to $-20^{\circ} \mathrm{C}$ over a duration of $4 \mathrm{~h}$, with a temperature gradient of $0.167^{\circ} \mathrm{C} / \mathrm{min}$. This temperature of $-20^{\circ} \mathrm{C}$ is maintained for $4 \mathrm{~h}$ and then increased to $+20^{\circ} \mathrm{C}$ over $4 \mathrm{~h}$, with a temperature gradient of $0.167^{\circ} \mathrm{C} / \mathrm{min}$; subsequently, the temperature of $+20^{\circ} \mathrm{C}$ is maintained for $4 \mathrm{~h}$ before starting the cycle again. This temperature cycle used for the artificial weathering experiments is shown in Figure 3.

2.3.2. CT Scanning Conditions. During the CTscanning of the mesostructures of rock samples subjected to freeze-thaw cycles, 20 layers were scanned at a time with an interval of $3.75 \mathrm{~mm}$. Figure 4 depicts the scanning locations. These scanning results do not consider the influence of artifacts and tolerance.

During the CT scan experiment, $3 \mathrm{~s}$ is required to scan each slice. A CT matrix is used to reconstruct the image, which has a resolution of $512 \times 512$. The thickness of the volume scanning layer is $5 \mathrm{~mm}$. The tube voltage determines the penetration of the X-ray; the higher the tube voltage is, the greater the $\mathrm{X}$-ray penetration is. For this experiment, a

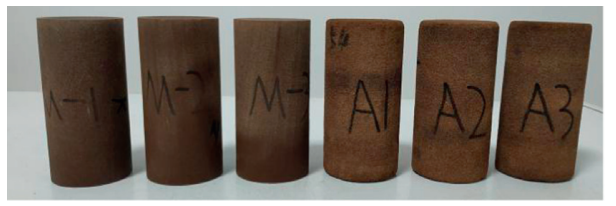

FIgURE 2: Two groups of red sandstone samples with different granularities.

tube voltage of $140 \mathrm{kV}$ is used. Spatial resolution refers to the smallest detail that can be resolved in an image. In this study, the spatial resolution was $6.8 \pm 20 \% \mathrm{LP} / \mathrm{cm}(10 \% \mathrm{MTF})$, which meets the requirements of identifying pore and fracture sizes in rock samples.

2.3.3. Experimental Procedure. The CT scanning experiments were aimed at observing the changes and damage in rock mesostructures under different freezing temperatures. The experimental process is as follows:

(1) The quality of the rock samples is weighed.

(2) The rock samples are dried at $105^{\circ} \mathrm{C}$ for $24 \mathrm{~h}$, after which the quality of the rock samples is weighed, and their natural water content is measured.

(3) The dried rock samples are saturated for $24 \mathrm{~h}$ at a temperature of $20^{\circ} \mathrm{C}$, followed by CT scanning and observation of sample microstructures prior to the freeze-thaw cycles.

(4) The rock samples are placed in the constant high- or low-temperature liquid bath and the temperature is lowered from $20^{\circ} \mathrm{C}$ to $-20^{\circ} \mathrm{C}$ over a course of $4 \mathrm{~h}$ and then maintained at $-20^{\circ} \mathrm{C}$ for $4 \mathrm{~h}$. Thereafter, the temperature is raised from $-20^{\circ} \mathrm{C}$ to $+20^{\circ} \mathrm{C}$ over $4 \mathrm{~h}$, and the rock samples are thawed for $4 \mathrm{~h}$ at $+20^{\circ} \mathrm{C}$, thus completing a single freeze-thaw cycle.

(5) The rock samples are subjected to CT scanning after 20, 40, 60, 80, and 100 freeze-thaw cycles.

It should be noted that each scan is performed using identical scanning parameters. As identical scanning positions are essential to track the structural evolution in a plane after different freeze-thaw cycles, we designed a scanner 
TABle 1: Physical parameters of rock samples.

\begin{tabular}{lccccc}
\hline Rock sample & Diameter $(\mathrm{mm})$ & Height $(\mathrm{mm})$ & Quality $(\mathrm{g})$ & Density $\left(\mathrm{g} / \mathrm{cm}^{3}\right)$ & Tensile strength $(\mathrm{MPa})$ \\
\hline M1 & 49.00 & 100.84 & 492.54 & 2.59 & 4.46 \\
M2 & 48.82 & 99.84 & 481.75 & 2.58 & 4.38 \\
M3 & 48.64 & 101.22 & 479.68 & 2.55 & 4.71 \\
A1 & 50.42 & 100.32 & 396.56 & 1.98 & 0.82 \\
A2 & 50.28 & 99.12 & 383.79 & 1.95 & 0.90 \\
A3 & 50.01 & 101.16 & 414.36 & 2.09 & 0.84 \\
\hline
\end{tabular}

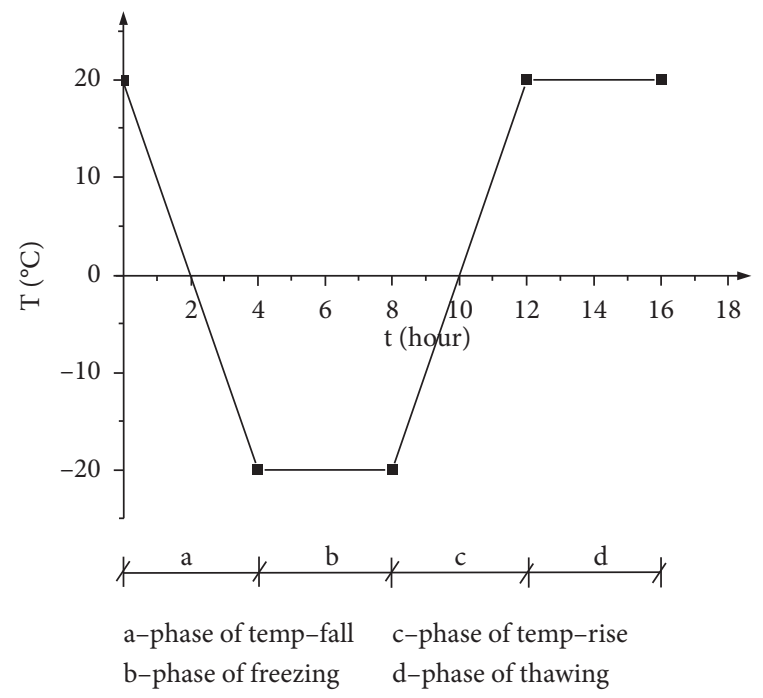

FIGURE 3: Temperature variations with respect to time over a single freeze-thaw cycle.

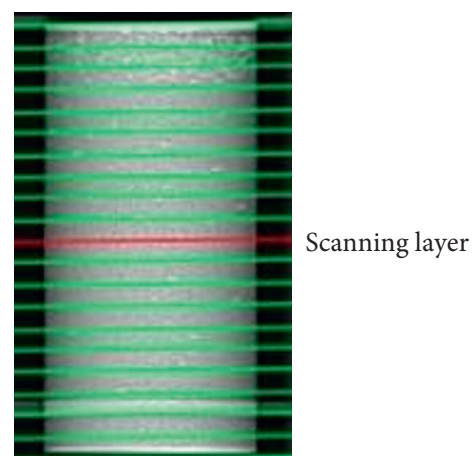

FIgURE 4: Spatial locations of CT scans for a rock subjected to freeze-thaw cycles.

bracket, as shown in Figure 2. The rock samples were placed in this scanner bracket, and the bracket was then placed at the same position on the scanner bed for each scan. Thus, changes in the internal microstructures of the rock samples could be observed appropriately.

2.4. Working Principle of CT. The radiation source and the detector are the primary components in a CT scanner. The $\mathrm{X}$-ray radiation emitted from the source can penetrate nonmetallic materials. The penetration ability of different $\mathrm{X}$-ray wavelengths is different, and the X-ray absorption ability of different substances varies. The higher the density of the material is and the higher the atomic number of the constituent matter is, the stronger its X-ray absorption ability is. When radiation emitted from the source penetrates an object, its radiation intensity decreases due to the absorption of the object. This can be described by the following equation:

$$
I=I_{0} e^{-\mu x}=I_{0} e^{-\mu_{m} \rho x}=\int_{0}^{E_{\max }} I_{0}(E) e^{-\int_{0}^{d} \mu(E) d s} \mathrm{~d} E,
$$

where $I_{0}$ is the light intensity before the X-rays penetrate the material $\left(\mathrm{ev} / \mathrm{m}^{2} \cdot \mathrm{s}\right), I$ is the light intensity after the X-rays penetrate the material $\left(\mathrm{ev} / \mathrm{m}^{2} \cdot \mathrm{s}\right), \mu_{m}$ is the absorption coefficient per unit mass of the detected material $\left(\mathrm{cm}^{2} / \mathrm{g}\right), \rho$ is the density of the material $\left(\mathrm{g} / \mathrm{cm}^{3}\right)$, and $x$ is the penetration length of the incident X-rays $(\mathrm{cm})$.

The absorption coefficient of the measured material per unit volume can be expressed as follows:

$$
\mu=\mu_{m} \rho
$$

where $\mu$ is the absorption coefficient of an object for X-rays; the absorption coefficient of water $\mu_{w}=\mu_{m}$.

The relationship between the X-ray absorption coefficient and CT number of the detected object can be expressed as follows:

$$
\mathrm{CT}(H)=\frac{\mu-\mu_{m}}{\mu_{m}} \times 1000 .
$$

During the operation of the CT scanner, the X-ray tube and the detector rotate around the center. X-rays emitted via the X-ray tube penetrate the cross section of the object and are converted photoelectrically. Thereafter, the analog signals thus obtained are converted to digital signals via an analog-to-digital converter. The converted projection data are then reconstructed based on a particular algorithm in order to obtain the reflection break. The quantitative data for the X-ray absorption coefficients of substances at various points on the surface are used to form a digital image of the scanning level in the object, $\mu$, in other words, a CT scan image.

The unit of CT values is $\mathrm{Hu}$, named after the inventor of CT, Professor Housfield [32]. The CT values of air, pure water, and ice are $-1000,0$, and $-100 \mathrm{Hu}$, respectively.

2.5. CT Image of Sandstone under Freeze-Thaw Conditions. CT divides a selected layer of an experimental rock sample into several cube-shaped blocks. These cube-shaped blocks are termed voxels. The density or gray level of each voxel, measured by the extent of X-ray penetration into the sample, 
is the basic unit of a CT image; this is also referred to as pixels. These voxels are arranged in rows to form an image matrix. When the X-ray beam passes through the selected plane, the voxels arranged along the penetration direction absorb the X-rays to a certain extent, causing attenuation of the X-ray beam. After the X-ray beam penetrates the scanning plane and is received by the detector on the opposite side, the amount of X-ray attenuation is determined as the sum of the attenuation values for all voxels along this direction. Subsequently, the X-ray tube rotates by a certain angle and emits a new X-ray beam in another direction; the detector on the opposite side then measures the sum of the $\mathrm{X}$-ray attenuation values for all of the voxels along this direction. Similarly, by repeating the X-ray scanning in different directions, the sum of the $\mathrm{X}$-ray attenuation values can be obtained. For the above process, an equation can be obtained for each scan. In this equation, the total X-ray attenuation is known, whereas the X-ray attenuation of each voxel contributing to this total attenuation is unknown. After several scans, a simultaneous equation can be obtained, which can be solved using a computer. Thus, the $\mathrm{X}$-ray attenuation value at each voxel can be obtained, which can then be converted into different gray levels of corresponding pixels through digital conversion. The layered matrix image thus formed using individual voxels represents the gray levels of structures with different densities.

\section{Experimental Results}

The original experimental data obtained via the CT scanning experiments are stored in the DICOM format and read from the CT machine. The pixels in the DICOM image are represented as twelve-bit binary information. The DICOM image contains sufficient microinformation, far beyond the scope of the human eye. However, this format cannot be displayed in conventional operating systems and is not recognized by typical graphics software. Thus, to clearly and intuitively observe the mesostructures of the frozen rock samples, it is necessary to convert the DICOM file format into a digital image format that can be visually inspected. Thus, the $\mathrm{VC}++$ program was employed to convert the image information and tools in the DICOM file to the BMP format; important information is read out and filled into the corresponding position in the newly created BMP file.

The CT images of the intermediate layers of samples M1 and A1 (as indicated by the red line in Figure 4) after the different freeze-thaw cycles are shown in Figures 5 and 6, respectively.

From the CT images of the frozen and thawed sandstones, the distribution of the microstructures is easily viewed. Specifically, pores, grain boundaries, microfissures, and mineral nodules are represented as high-density regions in these images. The disordered distribution of these characteristics results in an uneven initial rock microstructure. The difference in the mesostructures of the two rock samples is significant. Prior to the freeze-thaw cycles, the fine-grained red sandstone sample contains microcracks and pores, and the distribution of minerals is more uniform than that in the coarse-grained red sandstone sample; its initial damage is mainly due to cracks. In contrast, the mineral density of the coarse-grained red sandstone sample varies significantly, with a widespread distribution of mineral nodules; the pore size distribution is also different, and the pores are mainly due to interstitial voids. The initial damage in this sample is primarily caused by pores. It can be seen that as the number of freeze-thaw cycles increases, the porosity and cracks in samples M1 and A1 increase, leading to an amplification of existing damage and defects.

Under visual observation, the CT images of samples M1 and $\mathrm{A} 1$ after 20, 40, and 60 freeze-thaw cycles appear to be almost identical. When subjected to 40 freeze-thaw cycles, the samples underwent repeated volumetric changes, resulting in the movement and structural variations of different phases. The similar appearance of the CT images is attributed to the limited ability of the human eye in terms of differentiating among gray levels. Thus, microphysical information in the CT images could not be identified. To address this issue, a pseudo-color-enhancement method is employed; this method enables convenient and rapid identification of the microstructural and damage information in CT images.

\section{CT Image Enhancement Technology}

4.1. Pseudo-Color-Enhancement for CT Images. According to the Weber-Fresnel law, the relative contrast of vision can be expressed as

$$
C_{v}=\frac{S-S_{0}}{S_{0}}=\frac{K(\log B-\log B 0)}{K \log B 0+K 0},
$$

where $B$ and $B_{0}$ are the objective brightness of the object and the background, respectively, and $S$ and $S_{0}$ are the subjective brightness of the object and the background, respectively.

A logarithmic relationship exists between subjective brightness and objective brightness:

$$
S=K \log B+K_{0} .
$$

The visual resolution of the human eye mainly depends on the color and contrast of an image. The improvement in visual resolution by increasing contrast is also limited. According to equation (4), image enhancement can be achieved by increasing the number of colors. Therefore, the pseudo-color-enhancement for CT images transforms the 4096-level CT number of CT images into different colors depending on a linear or nonlinear mapping function. Thus, mesostructure and damage information in the CT images can be easily identified. For the observations, the different gray levels in CT images are visually transformed into different colors using a mapping function. As a result, image enhancement and target recognition can be achieved simultaneously.

Pseudo-color-enhancement of the sandstone CT images can be realized by constructing a transfer function and sum; establishing a mapping relationship between $R, G$, and B ratios and the gray levels; and synthesizing the pseudo-colorenhanced image. As shown in Figure 7, the gray level of the original image is transformed into three primary color 


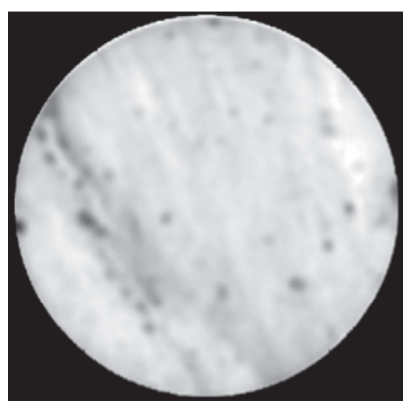

(a)

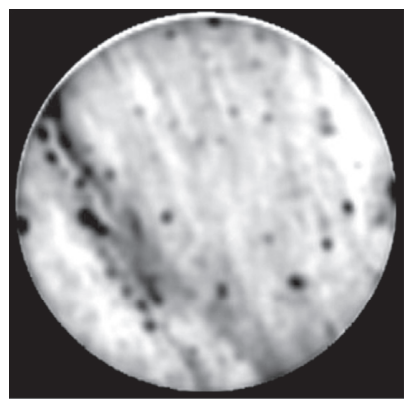

(d)

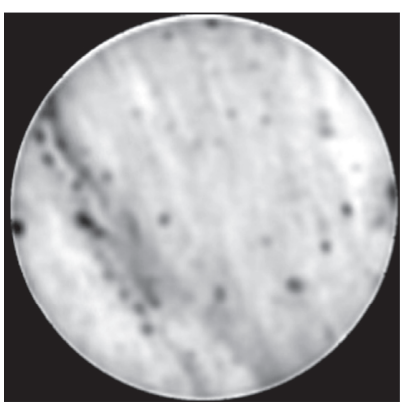

(b)

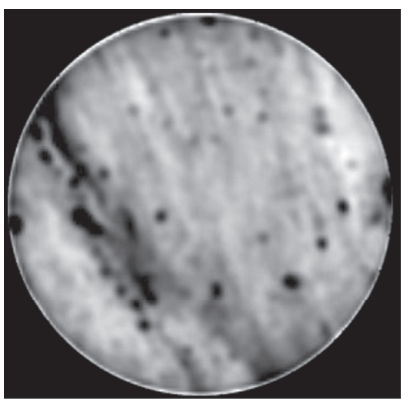

(e)

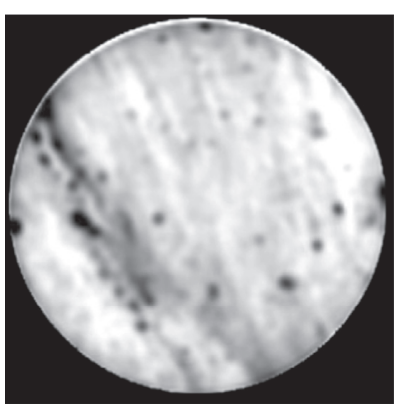

(c)

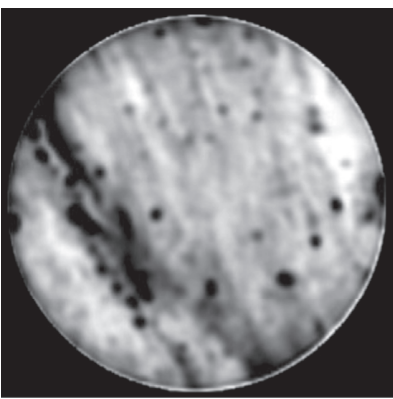

(f)

Figure 5: CT images of the $10^{\text {th }}$ slice of fine red sandstone M1 after freeze-thaw cycles. (a) 0 cycles. (b) 20 cycles. (c) 40 cycles. (d) 60 cycles. (e) 80 cycles. (f) 100 cycles.

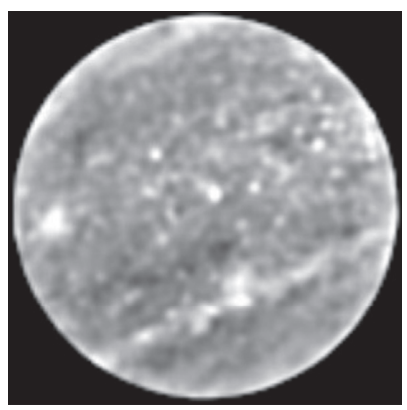

(a)

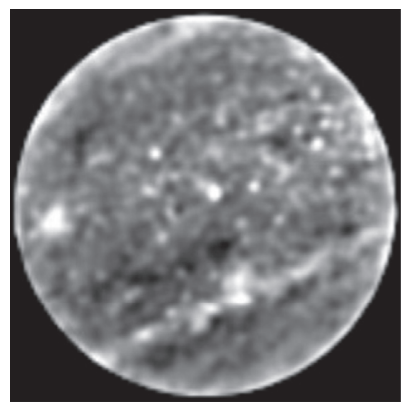

(d)

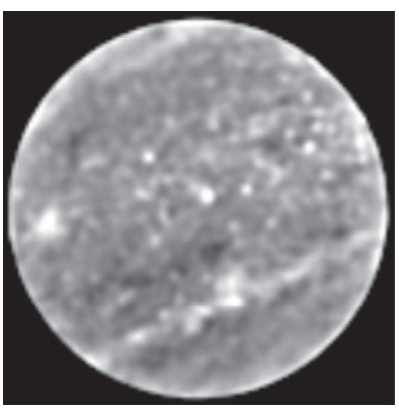

(b)

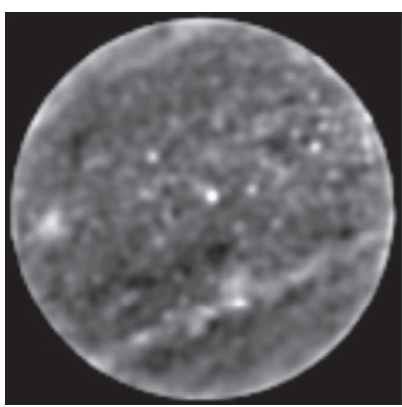

(e)

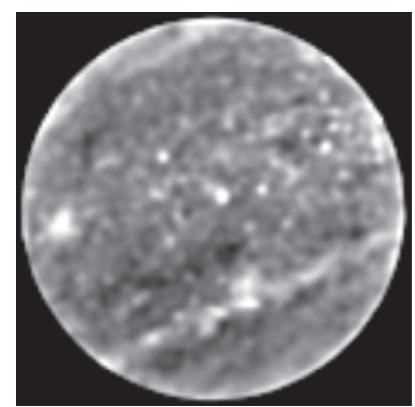

(c)

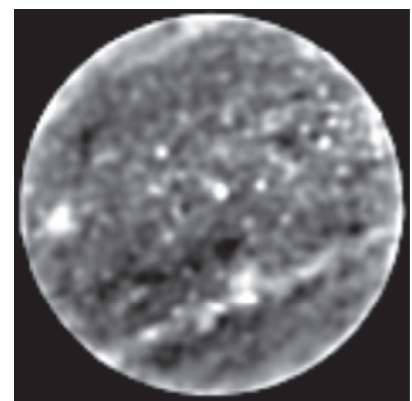

(f)

Figure 6: CT images of the $10^{\text {th }}$ slice of coarse red sandstone A1 after freeze-thaw cycles. (a) 0 cycles. (b) 20 cycles. (c) 40 cycles. (d) 60 cycles. (e) 80 cycles. (f) 100 cycles. 


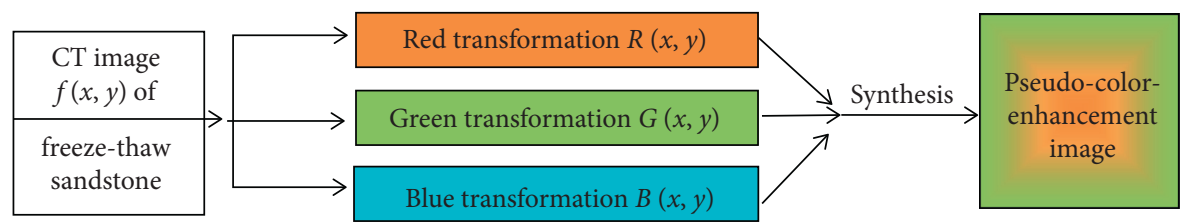

FIGURE 7: Flowchart of the transformation from gray level images to multicolor images.

components-red, green, and blue-through three transformations.

In this study, the transfer functions for converting gray levels to R, G, and B are defined as follows:

$$
\begin{aligned}
& I_{R}= \begin{cases}0, & g<1536, \\
\frac{g}{2}-768, & 1536 \leq g<2048, \\
255, & g \geq 2048,\end{cases} \\
& I_{G}= \begin{cases}0, & g<512, \\
\frac{g}{2}-256, & 512 \leq g<1024, \\
255, & 1024 \leq g<2048, \\
767-\frac{g}{4}, & 2048 \leq g<3072, \\
\frac{g}{4}-768, & g \geq 3072,\end{cases} \\
& I_{B}= \begin{cases}0, & g=0, \\
\frac{g}{2}-1, & 16 \leq g<512, \\
255, & 512 \leq g \leq 1024, \\
767-\frac{g}{2}, & 1024 \leq g<1536, \\
0, & 1536 \leq g<3072, \\
\frac{g}{4}-768, & g \geq 3072 .\end{cases}
\end{aligned}
$$

Equations (6), (7), and (8) are piecewise linear functions wherein the contents of the primary red, green, and blue colors are represented successively, and the CT value of the rock sample is represented as $g$. For a particular grayscale range, the absolute values of the basic color transfer function and slope remain constant at different times; this ensures that the synthesized color has a larger change step. Thus, changes in the mesostructures and the damage in the frozen and thawed rocks can be observed more easily.

4.2. Pseudo-Color-Enhancement of the CT Images of Sandstones Subjected to Freeze-Thaw Cycles. Using the abovementioned principle and method, pseudo-colorenhancement of the CT images of red sandstone samples M1 and A1 subjected to freeze-thaw cycles is realized, as shown in Figures 8 and 9, respectively.

From the pseudo-color-enhanced images, increased particle detachment, crack initiation, crack propagation, and porosity, which were caused by the volumetric expansion of water inside the rock, could be detected. In these images, rock particles are represented by the red portions, whereas areas of initial damage, such as the cracks and pores present prior to the freeze-thaw cycles, are represented by the green portions. As the number of freeze-thaw cycles increased, the cracks and pores expanded continuously, resulting in additional pores; thus, the original cracks and pores gradually propagate throughout the rock. The damaged area gradually changes from green to blue. The change in the color of the pseudo-color-enhanced images indicates the evolution of defects such as pores and fissures in the rock when subjected to freeze-thaw cycles and effectively reflects the change in rock mesostructures caused by such cycles.

\section{Discussion}

\subsection{Model of Damage Propagation in Sandstone under Freeze-Thaw Cycles}

5.1.1. Damage Characteristics. Pseudo-color-enhancement of the CT images indicates the degradation of the mesostructures due to the damage caused by different freeze-thaw cycles. Thus, the entire change in the rock mesostructures could be analyzed, including the particle detachment, crack initiation and propagation, and increased porosity caused by the volumetric expansion of water inside the rock. According to the experimental results, crack expansion occurs due to the repeated expansion and contraction of water, resulting in particle detachment around cracks (Figures 10 and 11). At a temperature of $-22^{\circ} \mathrm{C}$, under certain conditions, the theoretical pressure of ice in a closed system is $207 \mathrm{MPa}$ [33]. In practice, this pressure reaches $10-100 \mathrm{MPa}$ depending on factors such as the shape and roughness of cracks [34], properties of rocks, and air or salts present in the cavities. Regular rock has a tensile strength of approximately $10 \mathrm{MPa}$. Both red sandstone samples used in this study had a maximum tensile strength of $4.46 \mathrm{MPa}$. Thus, the pressure exerted due to water expansion inside the sandstone was sufficient for the propagation of cracks.

5.1.2. Different Damage Mechanisms in Two Sandstone Samples. In essence, a freeze-thaw cycle is a cycling of the temperature on different time scales, resulting in a cycle of frostheaving force in the porous sandstone changing from zero to a maximum and then back to zero. Three types of damage 


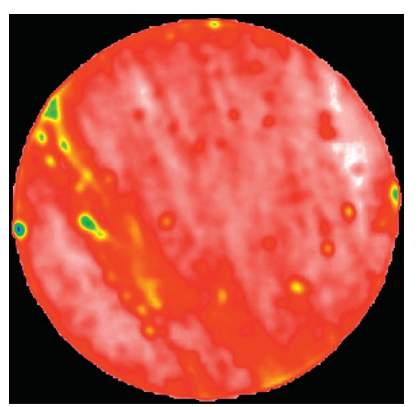

(a)

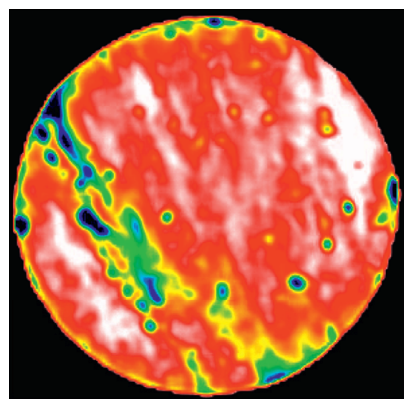

(d)

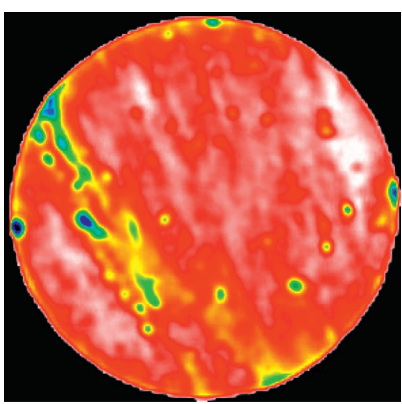

(b)

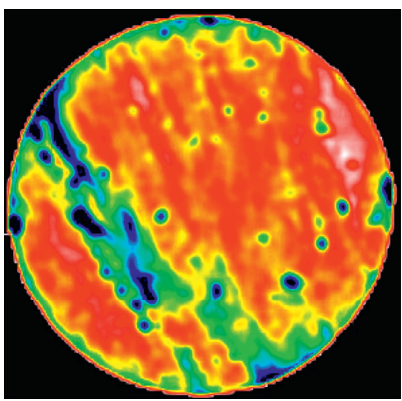

(e)

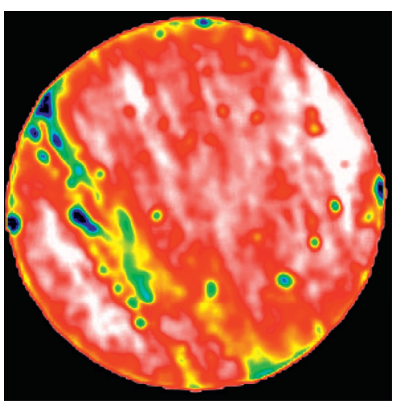

(c)

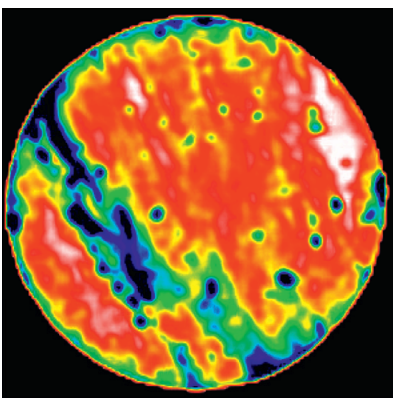

(f)

FIGURE 8: Pseudo-color-enhancement of CT images of the $10^{\text {th }}$ slice of sample M1 after freeze-thaw cycles. (a) 0 cycles. (b) 20 cycles. (c) 40 cycles. (d) 60 cycles. (e) 80 cycles. (f) 100 cycles.

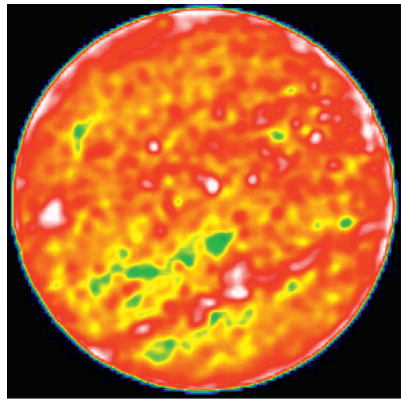

(a)

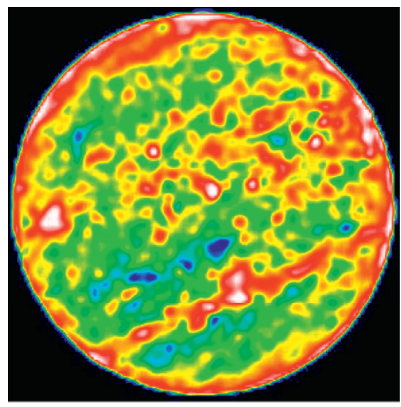

(d)

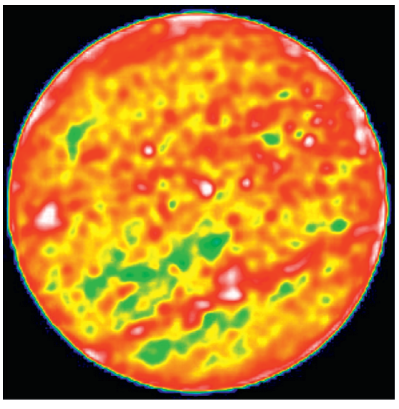

(b)

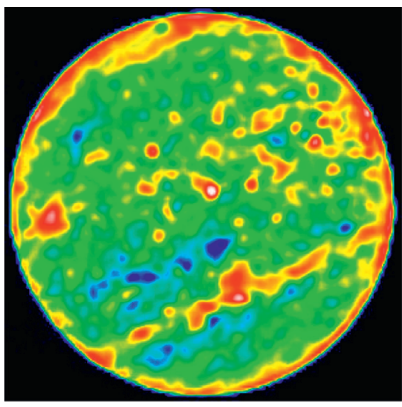

(e)

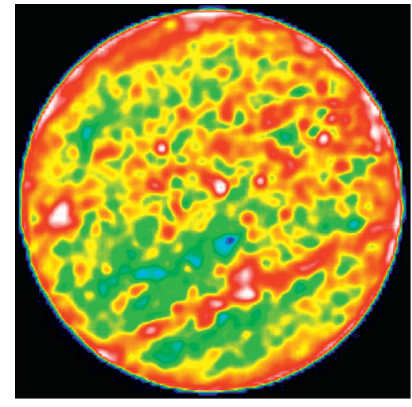

(c)

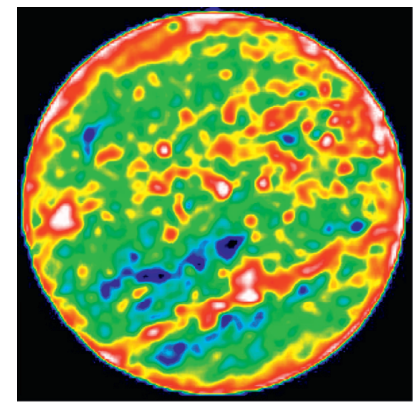

(f)

FIgURE 9: Pseudo-color-enhancement of CT images of the $10^{\text {th }}$ slice of sample A1 after freeze-thaw cycles. (a) 0 cycles. (b) 20 cycles. (c) 40 cycles. (d) 60 cycles. (e) 80 cycles. (f) 100 cycles.

mechanisms due to the free-thaw cycles can be readily identified via the pseudo-color-enhanced CT images: pores leading to fractures throughout the rock, mineral particles leading to weakly cemented portions falling off and the generation of additional pores, and fracture expansion leading to rock particles peeling off from the surface and noticeable macrodamage.

Under the action of freeze-thaw cycles, the two types of rock samples with different particle sizes exhibit different 


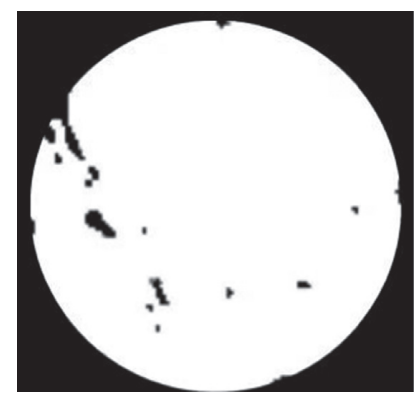

(a)

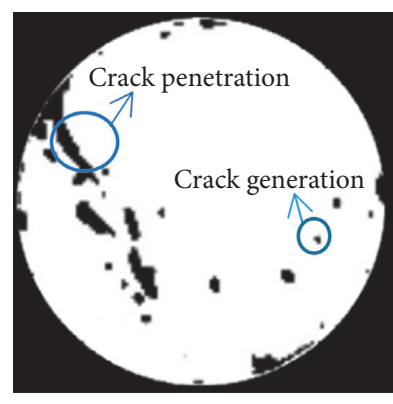

(b)

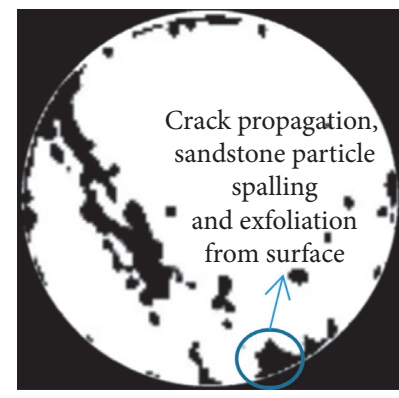

(c)

Figure 10: Degradation of the mesostructure of fine sandstone M1.

microstructural evolutions and damage propagation modes. The structure of the fine-grained sandstone (samples M1, M2, and M3) is relatively compact, with few internal holes (pores) and strong cementation of mineral rock particles. The initial damage in these samples is mainly due to fractures. Due to the freeze-thaw cycles, the volumetric expansion caused by the phase change of water promotes the propagation of existing fractures along cracks or joint surfaces, thereby forming a "trunk-side branch" structure. The closed ends of such side branches are conducive to volumetric expansion, making the sandstone more susceptible to damage due to freeze-thaw cycles. Deterioration of the effective bearing area is mainly concentrated near cracks. The rock and mineral particles in the coarse-grained sandstone samples (A1, A2, and A3) are large; thus, the cementation in this sandstone is weak, and the internal structure of the pores is relatively loose. The initial damage in this sandstone is mainly due to pores. Due to the freeze-thaw cycles, the volumetric expansion of water leads to the enhancement of initial pores (holes), and degradation of the effective bearing area occurs near these pores. As a result, the damaged areas are evenly distributed throughout the rock sample.

After 100 freeze-thaw cycles, macrocracks visible to the naked eye appeared on the surface of the fine-grained sandstone; however, even after several freeze-thaw cycles, peeling or macrocracks were not observed on the surface of the coarse-grained sandstone. Thus, the structure of the initial damage and the particle sizes of sandstone have a significant influence on the damage, as well as its mode, caused by freeze-thaw cycles.

In summary, different changes occurred in the two specimens owing to their initial structures. The pseudocolor-enhanced images also show that the freeze-thaw cycleinduced damage expansion in fine-grained red sandstone, dominated by fissures, and in coarse-grained red sandstone, dominated by pores, originating from existing damage or defects. This also led to different damage evolution patterns. In the fine red sandstone sample M1, the damage radiates and evolves from the initial cracks to the vicinity of primary cracks, with the aggravated damage area being concentrated near cracks. In the coarse-grained red sandstone sample A1, damage develops along the pores. As the number of freezethaw cycles increases, the distribution of the damaged areas is more widespread compared to that in the fine-grained red sandstone; the damaged areas also extend more rapidly. Therefore, rock microstructures have a significant influence on the size, extent, and evolution of damage.

5.1.3. Damage Propagation Model. Under freeze-thaw cycles, the structural deterioration of sandstone is mainly caused by the generation, penetration, aggregation, and extension of internal microcracks. Naturally occurring cracks in sandstone mainly include pores and microfissures. Under cyclic external temperatures and loading, these microcracks continuously propagate, leading to the generation of additional microcracks. All these microcracks are expected to eventually develop into macrocracks. Under low-temperature conditions, frost-heaving forces and thermal stresses are the primary causes of structural damage in sandstone. Based on the experimental results, a conceptual model for the structural deterioration in sandstone is presented as a schematic in Figure 12.

Pores and cracks occur naturally in sandstone (Figures 12(a) and 12(b)). When red sandstone is in a waterrich environment, water enters its pore network until the sandstone is completely saturated. At low temperatures (Figure 12(b)), the water in these pores freezes, which results in volumetric expansion and frost heaving. The ice thus formed in the pores expands by approximately $9 \%$ and can generate significant frost-heaving stresses. If more than $90 \%$ of the pore volume is occupied by water, the volumetric expansion of water exerts pressure on the pore walls. When this pressure exceeds the tensile strength of the rock, cracking occurs, and the pore walls are destroyed; this leads to the propagation of existing cracks. This is illustrated in Figure 12(c), which shows that the existing cracks expand and elongate. In addition, low temperatures can generate thermal stress, which may create additional cracks oriented perpendicular to the existing cracks (a).

5.1.4. Prediction of Microstructure and Damage Evolution. According to the damage propagation mode of the sandstone samples subjected to freeze-thaw cycles, we can predict the damage propagation trend in sandstone beyond 100 freeze-thaw cycles. Thus, prediction maps of damage propagation patterns for two different rocks with cracks and 


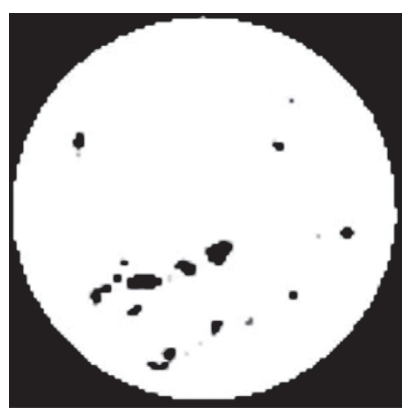

(a)

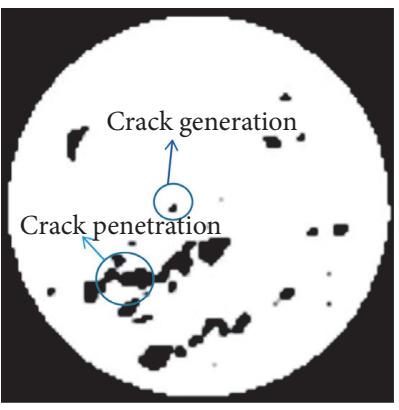

(b)

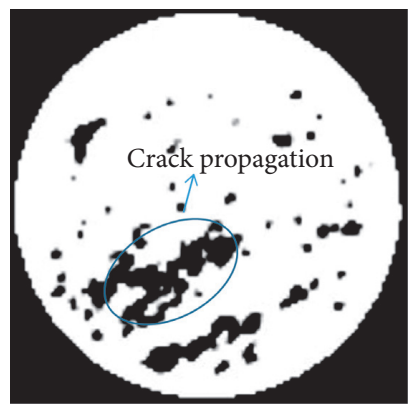

(c)

FIGURE 11: Degradation of the mesostructure of fine sandstone A1.

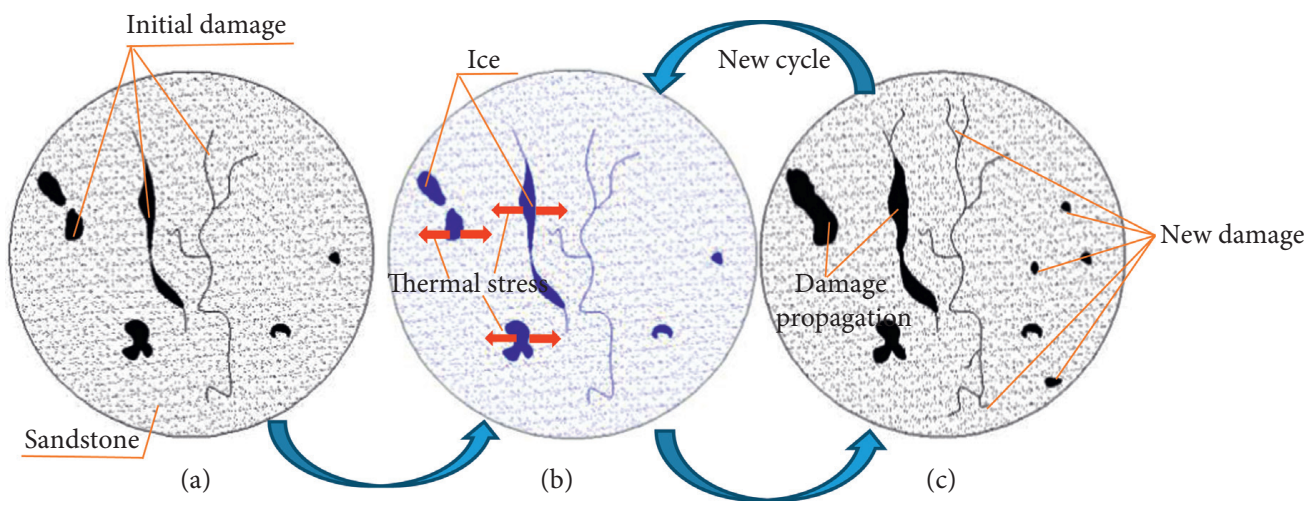

Figure 12: Conceptual model of the freeze-thaw deterioration process. (a) Initial damage; (b) volumetric expansion after the water has frozen; (c) damage propagation.

pores as the dominant defects are obtained after 100 freezethaw cycles, as shown in Figures 13 and 14, respectively.

\subsection{Quantitative Analyses of Mesostructure Damage.} Based on the concept of continuity and effective stress proposed by Davidson [33], a volume unit that can represent the damage characteristics of the material is selected. The area of defects (such as micropores and microcracks) along the section is denoted as $A_{D}$, and the total area of the section is $A$. Thus, the effective bearing area of the section is $A^{*}=A-A_{D}$. Based on the damage mechanics theory, a freeze-thaw damage variable, $D_{f}$, which is based on the area of pores (fissures), is defined to describe the influence of freeze-thaw cycles on rock damage. $D_{f}$ can be expressed as follows:

$$
D_{f}=\frac{A_{D}}{A}
$$

where $A_{D}$ represents the damaged area in the scanning section; in these CT experiments, $A$ is $1884.75 \mathrm{~mm}^{2}$ for sample M1 and $1995.6 \mathrm{~mm}^{2}$ for sample A1.

In the pseudo-color-enhanced image, the blue and green areas represent the damaged areas, which can be determined by counting the number of blue and green pixels in the pseudo-color-enhanced image (shown in Figures 10 and 11). Based on the relationship between the total number of pixels and the total area of the scanning layer, Table 2 can be obtained.

From Table 2, Figure 15 can be obtained. When the number of freeze-thaw cycles is 0 , the degree of damage in the mesostructures of the two rock samples is not zero, which indicates that initial damage exists in the samples, even before the freeze-thaw cycles. This is consistent with the actual scenarios of this study. The initial damage in the coarse sandstone sample A1 is greater than that in the fine sandstone sample M1. In M1 and A1, mesostructure damage increases with the number of freeze-thaw cycles. For the same number of freeze-thaw cycles, the degree of mesostructure damage in the coarse-grained sandstone sample A1 is greater than that in the fine-grained sandstone sample $\mathrm{M} 1$; this is because the former has a greater amount of initial damage as compared to the latter. In terms of the number of damaged areas in the mesostructures, M1 and A1 exhibit the same trend of an initial increase followed by a decrease. Depending on the initial damage, the freeze-thaw cycles promote the emergence of additional damaged areas. The number of damaged areas is the highest after 60 freeze-thaw cycles. As the number of freeze-thaw cycles increases, the damaged areas are penetrated, and thus the number of damaged areas in the mesostructure decreases. Thus, it can be concluded that the initial damage and the number of freeze-thaw cycles are key factors affecting damage propagation in sandstone microstructures in a low-temperature environment. Further studies should focus 


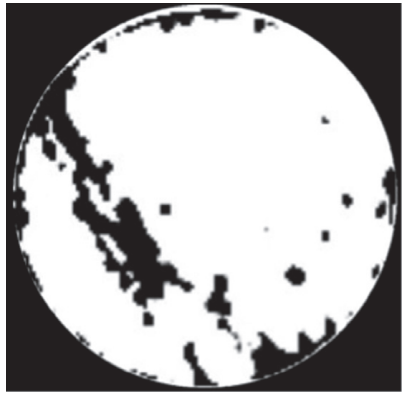

(a)

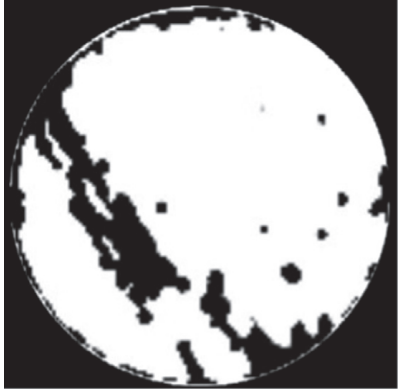

(b)

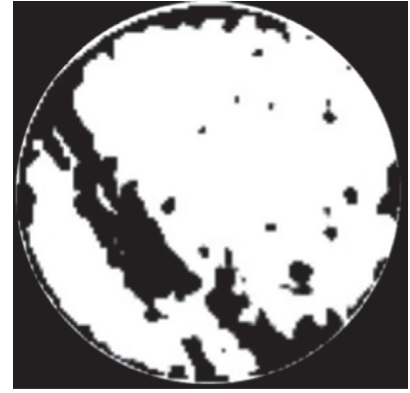

(c)

FIgURE 13: Prediction maps of damage propagation in fine red sandstone M1. (a) 140 cycles. (b) 180 cycles. (c) 200 cycles.

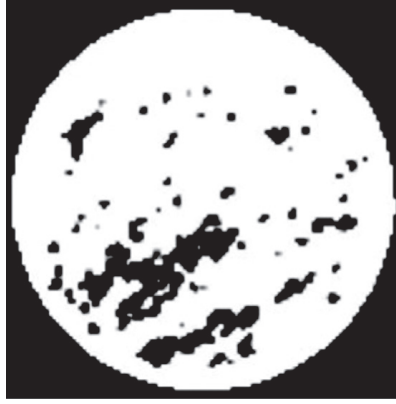

(a)

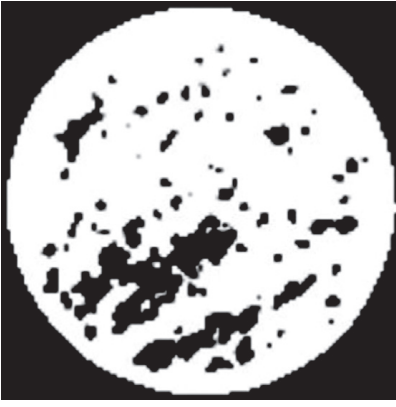

(b)

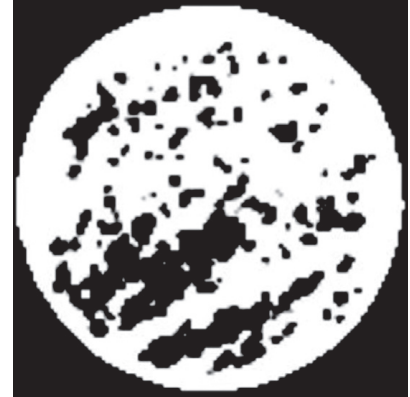

(c)

Figure 14: Prediction maps of damage propagation in coarse red sandstone A1. (a) 140 cycles. (b) 180 cycles. (c) 200 cycles.

TABle 2: Damage variables and number of damage regions.

\begin{tabular}{|c|c|c|c|c|c|c|}
\hline \multirow{2}{*}{ Freeze-thaw cycles } & \multicolumn{3}{|c|}{ Fine-grained sandstone M1 } & \multicolumn{3}{|c|}{ Coarse-grained sandstone A1 } \\
\hline & $A_{D}\left(\mathrm{~mm}^{2}\right)$ & Number of damage regions, $N$, & $D_{f}(\%)$ & $A_{D}\left(\mathrm{~mm}^{2}\right)$ & Number of damage regions, $N$ & $D_{f}(\%)$ \\
\hline 0 & 23.60 & 11 & 1.25 & 32.76 & 17 & 1.64 \\
\hline 20 & 45.21 & 14 & 2.39 & 114.72 & 25 & 5.74 \\
\hline 40 & 93.18 & 23 & 4.94 & 560.07 & 39 & 28.06 \\
\hline 60 & 175.83 & 25 & 9.33 & 830.64 & 26 & 41.62 \\
\hline 80 & 469.71 & 20 & 24.92 & 902.07 & 17 & 45.20 \\
\hline 100 & 497.40 & 19 & 26.39 & 1417.56 & 5 & 71.03 \\
\hline
\end{tabular}
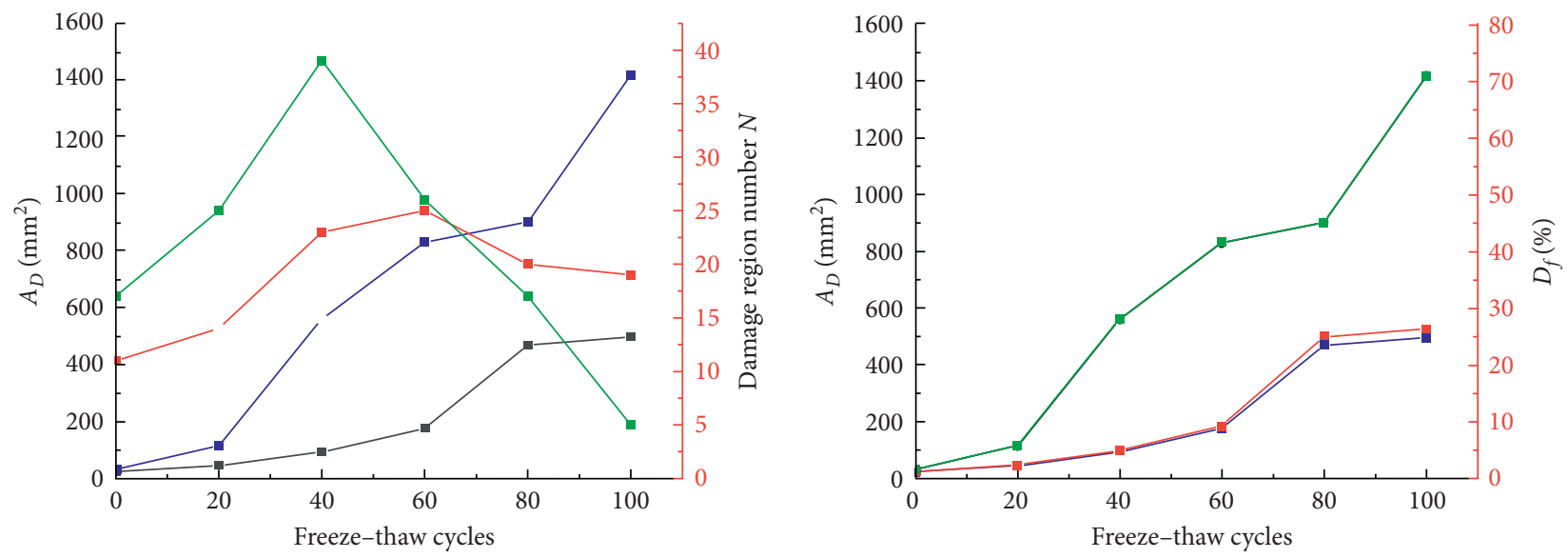

$$
\begin{array}{ll}
--A_{D} \text { of } \mathrm{M} 1 & -N \text { of } \mathrm{M} 1 \\
--A_{D} \text { of } \mathrm{A} 1 & -
\end{array}
$$$$
\begin{array}{ll}
--A_{D} \text { of } \mathrm{M} 1 & --D_{f} \text { of } \mathrm{M} 1 \\
-\bullet-A_{D} \text { of } \mathrm{A} 1 & --D_{f} \text { of } \mathrm{A} 1
\end{array}
$$

Figure 15: Freeze-thaw damage variable curves with respect to the number of freeze-thaw cycles. 
on the deterioration of the mechanical properties of the two rock types under external loading.

\section{Conclusions}

In this study, the detrimental impact of consecutive freezethaw cycles on the mesostructures of sandstone was investigated via CT scanning and image processing techniques. As the initial damage in sandstone is an important parameter influencing its properties, variations in the mesostructures and the damage propagation under different freeze-thaw cycles were discussed. The conclusions can be summarized as follows:

(1) CT scanning experiments with sandstones were conducted; CT images were obtained after subjecting the sandstone samples to $0,20,40,60,80$, and 100 freeze-thaw cycles. These images served as the basis for digital descriptions of rock mesostructures and quantitative analyses of damage evolution under freeze-thaw cycles.

(2) Based on digital image processing theory and methods, CT images of the sandstones subjected to different freeze-thaw cycles were analyzed. Subsequently, pseudo-color-enhancement of these CT images was realized. Particle detachment, crack initiation and propagation, and increased porosity, which were caused by the volumetric expansion of water inside the rocks, were detected using these pseudo-color-enhanced CT images. Microphysical information contained in the CT images was exploited to enable quantitative evaluations of the size and spatial positions of rock damage, and the corresponding expressions were also elucidated.

(3) A damage evolution model for sandstone mesostructures under freeze-thaw conditions was proposed. The mesostructures of sandstone were found to have a significant influence on the size, extent, and evolution of damage. The evolution of damage due to freeze-thaw cycles mainly extended along existing damaged/defect areas in the sandstone. As the number of freeze-thaw cycles increased, the distribution of damage in coarse-grained red sandstone was more widespread than that in fine-grained red sandstone; moreover, the expansion of the damaged area in the former was more rapid than that in the latter.

(4) Damage factors expressed by mesodamage were determined, and the influence of freeze-thaw cycles on the damage characteristics of sandstone was discussed. The initial damage in sandstone and the number of freeze-thaw cycles were determined to be the most important factors influencing the damage in sandstone mesostructures. Furthermore, the damage variable defined herein can be used to describe the dynamic damage evolution in sandstone mesostructures when subjected to freeze-thaw cycles.
The proposed novel method for evaluating damage evolution in rock mesostructures under cyclic temperatures is also suitable for conducting stability and safety evaluations of open-system frozen soil engineering projects.

\section{Data Availability}

The data used to support the findings of this study are included within the article.

\section{Conflicts of Interest}

The authors declare that there are no conflicts of interest regarding the publication of this paper.

\section{Acknowledgments}

This work was supported by the National Key R\&D Program of China (Grant no. 2018YFC0808705), the National Natural Science Foundation of China (Grant nos. 41702339, 51774231, 41971095, 41702334, and 11872299), and the project supported by Natural Science Basic Research Plan in Shaanxi Province of China (Grant nos. 2018JQ4026 and 2020JZ-53).

\section{References}

[1] Y. Lai, X. Zhang, W. Yu, S. Zhang, Z. Liu, and J. Xiao, “Threedimensional nonlinear analysis for the coupled problem of the heat transfer of the surrounding rock and the heat convection between the air and the surrounding rock in cold-region tunnel," Tunnelling and Underground Space Technology, vol. 20, no. 4, pp. 323-332, 2005.

[2] H. Lin, H. Yang, Y. Wang, Y. Zhao, and R. Cao, "Determination of the stress field and crack initiation angle of an open flaw tip under uniaxial compression," Theoretical and Applied Fracture Mechanics, vol. 104, pp. 1-13, 2019.

[3] J. Wang and D. Niu, "Inflfluence of freeze-thaw cycles and sulfate corrosion resistance on shotcrete with and without steel fifiber," Construction \& Building Materials, vol. 30, no. 122, pp. 628-636, 2016.

[4] Z. Zhou, W. Ma, S. Zhang, Y. Mu, and G. Li, "Effect of freezethaw cycles in mechanical behaviors of frozen loess," Cold Regions Science and Technology, vol. 146, no. 146, pp. 9-18, 2018.

[5] Y. Shen, H. Yang, J. Xi, Y. Yang, Y. Wang, and X. Wei, “A novel shearing fracture morphology method to assess the influence of freeze-thaw actions on concrete-granite interface," Cold Regions Science and Technology, vol. 169, Article ID 102900, 2019.

[6] N. Matsuoka, "Microgelivation versus macrogelivation: towards bridging the gap between laboratory and field frost weathering," Permafrost and Periglacial Processes, vol. 12, no. 3, pp. 299-313, 2001.

[7] K.-P. Zhou, B. Li, J.-L. Li, H.-E. Deng, and F. Bin, "Microscopic damage and dynamic mechanical properties of rock under freeze-thaw environment," Transactions of Nonferrous Metals Society of China, vol. 25, no. 4, pp. 1254-1261, 2015.

[8] R. Cao, R. Yao, J. Meng, Q. Lin, H. Lin, and S. Li, "Failure mechanism of non-persistent jointed rock-like specimens under uniaxial loading: laboratory testing," International Journal of Rock Mechanics and Mining Sciences, vol. 132, pp. 1-15, 2020. 
[9] F. Mustafa and I. Ismail, "Effects of the freeze-thaw (F-T) cycle on the andesitic rocks (sille-Konya/Turkey) used in construction building," Journal of African Earth Sciences, vol. 9, no. 109, pp. 96-106, 2015.

[10] R. Altindag, I. S. Alyildiz, and T. Onargan, "Mechanical property degradation of ignimbrite subjected to recurrent freeze-thaw cycles," International Journal of Rock Mechanics and Mining Sciences, vol. 41, no. 6, pp. 1023-1028, 2004.

[11] A. Binal and K. E. Kasapoglu, "Effects of freezing and thawing process on physical and mechanical properties of selime ignimbrite outcrops in aksaray-ihlara valley in Turkish]," in Proceeding of 6th Regional. Rock Mechanic Symposium, pp. 189-196, Konya, Turkey, October 2002.

[12] Z. Karaca, A. Hamdi Deliormanli, H. Elci, and C. Pamukcu, "Effect of freeze-thaw process on the abrasion loss value of stones," International Journal Of Rock Mechanics And Mining Sciences, vol. 47, no. 7, pp. 1207-1211, 2010.

[13] M. Hori and H. Morihiro, "Micromechanical analysis on deterioration due to freezing and thawing in porous brittle materials," International Journal of Engineering Science, vol. 36, no. 4, pp. 511-522, 1998.

[14] Y. Shen, Y. Wang, X. Wei, H. Jia, and R. Yan, "Investigation on meso-debonding process of the sandstone-concrete interface induced by freeze-thaw cycles using NMR technology," Construction and Building Materials, vol. 252, Article ID 118962, 2020.

[15] J.-J. Dong, J.-Y. Hsu, W.-J. Wu et al., "Stress-dependence of the permeability and porosity of sandstone and shale from TCDP hole-A," International Journal of Rock Mechanics and Mining Sciences, vol. 47, no. 7, pp. 1141-1157, 2010.

[16] H.-l. Wang, W.-j. Chu, and M. He, "Anisotropic permeability evolution model of rock in the process of deformation and failure," Journal of Hydrodynamics, vol. 24, no. 1, pp. 25-31, 2012.

[17] H. L. Wang and W. Y. Xu, "Permeability evolution laws and equations during the course of deformation and failure of brittle rock," Journal of Engineering Mechanics, vol. 139, no. 11, pp. 1621-1626, 2013.

[18] A. Rabbani and S. Jamshidi, "Specific surface and porosity relationship for sandstones for prediction of permeability," International Journal of Rock Mechanics and Mining Sciences, vol. 71, pp. 25-32, 2014.

[19] S. Yu and X. Feng, Damage Mechnical, Tsinghua University Press, Beijing, China, 1997, in Chinese.

[20] G. Yang and C. Zhang, Rock Damage and Detection, Science and Technology Press, Xi'an, Shaanxi, China, 1998, in Chinese.

[21] S. Xie, H. Lin, Y Chen et al., "A damage constitutive model for shear behavior of joints based on determination of the yield point," International Journal of Rock Mechanics and Mining Sciences, vol. 12812 pages, 2020.

[22] S. Raynaud, Y. G. Mazerolle, D. Fabre, F. Mazerolle, Y. Geraud, and H. J. Latière, "Analysis of the internal structure of rocks and characterization of mechanical deformation by a non-destructive method: X-ray tomodensitometry," Tectonophysics, vol. 159, no. 1-2, pp. 149-159, 1989.

[23] G. S. Yang, D. Y. Xie, C. Q. Zhang et al., "Quantitative analysis of distribution regulation of CT values of rock damage," Chinese Journal of Rock Mechanics \& Engineering, vol. 17, no. 3, pp. 279-285, 1998, in Chinese.

[24] G. S. Yang and H. Liu, "Study on the rock damage characteristics based on the technique of CT image processing," Journal of China Coal Society, vol. 32, no. 5, pp. 463-468, 2007, in Chinese.
[25] X. Ge, J. Ren, Y. Pu et al., "Real-time CT testing for the mesodamage propagation characteristics of rock," Science in China: Series E, vol. 30, no. 2, pp. 104-111, 2000, in Chinese.

[26] Z. Kang, Y. Zhao, Q. Meng et al., "Micro-CT experimental research of oil shale thermal cracking laws," Chinese Journal of Geophysics, vol. 52, no. 3, pp. 842-848, 2009.

[27] L. Yang, J. Zhao, W. Liu, Y. Li, M. Yang, and Y. Song, "Microstructure observations of natural gas hydrate occurrence in porous media using microfocus X-ray computed tomography," Energy \& Fuels, vol. 29, no. 8, pp. 4835-4841, 2015.

[28] Y. Watanabe, N. Lenoir, J. Otani, and T. Nakai, "Displacement in sand under triaxial compression by tracking soil particles on X-ray CT data," Soils and Foundations, vol. 52, no. 2, pp. 312-320, 2012.

[29] H.-Y. Zhang, W.-J. Xu, and Y.-Z. Yu, "Triaxial tests of soilrock mixtures with different rock block distributions," Soils and Foundations, vol. 56, no. 1, pp. 44-56, 2016.

[30] T. Ma, C. Yang, P. Chen, X. Wang, and Y. Guo, "On the damage constitutive model for hydrated shale using CT scanning technology," Journal of Natural Gas Science and Engineering, vol. 28, pp. 204-214, 2016.

[31] Y. Wang, X. Li, B. Zhang, and Y. Wu, "Meso-damage cracking characteristics analysis for rock and soil aggregate with CT test," Science China Technological Sciences, vol. 57, no. 7, pp. 1361-1371, 2014.

[32] L. Q. C. Nguyen, N. H. Minh, M. C. Hoang et al., "Porosity estimation from high resolution CT Scan images of rock samples by using housfield unit," Geology, vol. 8, no. 10, pp. 1019-1026, 2018.

[33] G. P. Davidson and J. F. Nye, "A photoelastic study of ice pressure in rock cracks," Cold Regions Science and Technology, vol. 11, no. 2, pp. 141-153, 1985.

[34] L. Kachanov, Introduction to Continuum Damage Mechanics, Springer Science \& Business Media, Berlin, Germany, 2013. 